\title{
Obstetrical brachial plexus injury: burden in a publicly funded, universal healthcare system
}

\author{
Christopher J. Coroneos, MD, MSc, ${ }^{1,2}$ Sophocles H. Voineskos, MD, MSc, ${ }^{1,2}$ \\ Marie K. Coroneos, MD, ${ }^{3}$ Noor Alolabi, MD, ${ }^{1}$ Serge R. Goekjian, MD, ${ }^{1}$ Lauren I. Willoughby, MD, ${ }^{1}$ \\ Forough Farrokhyar, MPhil, PhD, ${ }^{2,4}$ Achilleas Thoma, MD, MSc, ${ }^{1,2}$ James R. Bain, MD, MSc, ${ }^{1}$ \\ Melissa C. Brouwers, MA, PhD, ${ }^{2,5}$ on behalf of the Canadian OBPI Working Group
}

${ }^{1}$ Division of Plastic Surgery and Departments of ${ }^{2}$ Clinical Epidemiology \& Biostatistics, ${ }^{4}$ Surgery, and ${ }^{5}$ Oncology, McMaster
University, Hamilton, Ontario, Canada; and ${ }^{3}$ Department of Obstetrics and Gynecology, University of Toronto, Ontario, Canada

OBJECTIVE The aim of this study was to determine the volume and timing of referrals for obstetrical brachial plexus injury (OBPI) to multidisciplinary centers in a national demographic sample. Secondarily, we aimed to measure the incidence and risk factors for OBPI in the sample. The burden of OBPI has not been investigated in a publicly funded system, and the timing and volume of referrals to multidisciplinary centers are unknown. The incidence and risk factors for OBPI have not been established in Canada.

METHODS This is a retrospective cohort study. The authors used a demographic sample of all infants born in Canada, capturing all children born in a publicly funded, universal healthcare system. OBPI diagnoses and corresponding risk factors from 2004 to 2012 were identified and correlated with referrals to Canada's 10 multidisciplinary OBPI centers. Quality indicators were approved by the Canadian OBPI Working Group's guideline consensus group. The primary outcome was the timing of initial assessment at a multidisciplinary center, "good" if assessed by the time the patient was 1 month of age, "satisfactory" if by 3 months of age, and "poor" if thereafter. Joinpoint regression analysis was used to determine the OBPI incidence over the study period. Odds ratios were calculated to determine the strength of association for risk factors.

RESULTS OBPI incidence was 1.24 per 1000 live births, and was consistent from 2004 to 2012. Potential biases underestimate the level of injury identification. The factors associated with a very strong risk for OBPI were humerus fracture, shoulder dystocia, and clavicle fracture. The majority (55\%-60\%) of OBPI patients identified at birth were not referred. Among those who were referred, the timing of assessment was "good" in $28 \%$, "satisfactory" in $66 \%$, and "poor" in $34 \%$.

CONCLUSIONS Shoulder dystocia was the strongest modifiable risk factor for OBPI. Most children with OBPI were not referred to multidisciplinary care. Of those who were referred, $72 \%$ were assessed later than the target quality indicator of 1 month that was established by the national guideline consensus group. A referral gap has been identified using quality indicators at clinically relevant time points; this gap should be addressed with the use of knowledge tools (e.g., a clinical practice guideline) to target variations in referral rates and clinical practice. Interventions should guide the referral process.

http://thejns.org/doi/abs/10.3171/2015.6.PEDS14703

KEY WORDS arm growth and development; birth injuries; brachial plexus injuries; child; humans; infant; newborn; peripheral nerve

$\mathrm{O}$ BSTETRICAL brachial plexus injury (OBPI) is reported in $0.4-5.8$ per 1000 births, ${ }^{26,32}$ varying with the study type and the availability of maternalfetal care. ${ }^{23,35,49}$ The incidence of OBPI is equivalent to that of autism ${ }^{52}$ and congenital profound hearing loss ${ }^{53}$ it is greater than Type 1 diabetes,${ }^{51}$ cystic fibrosis, ${ }^{27}$ and the combined incidence of congenital disorders tested for in newborn screening. ${ }^{53}$ Accepted risk factors include dystocia, increased fetal size, prolonged labor, difficult or instrumented delivery, and comorbid fetal trauma. ${ }^{29}$

The Canadian OBPI Working Group has endeavored to develop a clinical practice guideline for the treatment of

ABBREVIATIONS AAPC = average annual percent change; $\mathrm{OBPI}=$ obstetrical brachial plexus injury

SUBMITTED December 14, 2014. ACCEPTED June 11, 2015.

INCLUDE WHEN CITING Published online October 23, 2015; DOI: 10.3171/2015.6.PEDS14703. 
OBPI. One of the management "gaps" identified for OBPI is the timely referral to multidisciplinary care. ${ }^{7}$ Primary care providers can underestimate the injury, failing to objectively characterize residual impairment ${ }^{44}$ and providing guardians with inaccurate information and education. ${ }^{9,18}$ This results in guardian distress and delayed specialist referral. ${ }^{44}$ While the benefits of early referral have been investigated internationally, ${ }^{44}$ the proportion of infants referred to multidisciplinary centers and the process indicators for doing so have not been established.

National administrative databases are in place to quantify the incidence and risk factors for birth trauma. Clinic-based audits have been demonstrated to improve perinatal care. ${ }^{40}$ Organizational databases are maintained for institutions' OBPI clinics, reflecting clinic processes and single-provider surgeon and therapist outcomes. The primary objective of this study was to measure the volume and timing of OBPI referrals to Canadian multidisciplinary centers. Timing was assessed relative to quality indicators established by experts in the guideline group. The secondary objective was to determine the incidence and risk factors for OBPI in Canada. This study will help guide formation of a clinical practice guideline by addressing limitations in the literature, generating and measuring quality indicators for care processes, providing a robust analysis of the incidence trend, and expressing risk factors with strength of association.

\section{Methods \\ Personnel}

The Canadian OBPI Working Group was established to participate in clinical practice guideline development, implementation, and networking for research. It is composed of national OBPI opinion leaders, who are lead physicians at each of Canada's 10 OBPI multidisciplinary centers. Early in the guideline development process, this consensus group (Appendix 1) suggested that a formal analysis of the Canadian burden of OBPI should be conducted and reported in this study to help inform recommendations. Guideline publication is forthcoming. ${ }^{19}$

\section{Data Sources}

The national incidence and risk factor data were obtained from the Canadian Institute for Health Information (CIHI) Discharge Abstract Database (DAD) and Hospital Morbidity Database (HMDB) (http://www.cihi. ca/CIHI-ext-portal/internet/en/document/types+of+care/ hospital+care/acute+care/dad_metadata), during the years 2004 to 2012. This database contains administrative, clinical, and demographic data from all acute-care facility discharges nationally; children born outside of hospitals are not reliably captured in this database. The data are unweighted, and the database reflects every birth. Reporting is mandatory except in the province of Quebec. Excluding Quebec, reporting has been nationally consistent since 2004-2005 using the International Statistical Classification of Diseases and Related Health Problems, Tenth Revision, Canada (ICD-10-CA) classification system. Quebec adopted ICD-10-CA in 2006-2007; earlier data are inconsistent with current reporting.

\section{Variables}

All newborn and corresponding maternal records were identified in the CIHI database. Stillbirths and therapeutic abortions were excluded. Records were stratified by province/territory to enable comparison with multidisciplinary center referrals. OBPI cases were identified by ICD-10CA codes (Appendix 2).

Risk factors were generated from a previous epidemiological study ${ }^{29}$ and from studies in our systematic review ${ }^{18}$ with a primary outcome of OBPI incidence or risk. ${ }^{1-3,5,6,16,21,23,26,30,32,34,35,38,41,47-49,57-59,62,65}$ Cases of macrosomia, clavicle facture, and humerus fracture were identified within all newborn records (Appendix 2). Classifications of heavy for gestational age (not macrosomia), fetal or birth asphyxia, and intracranial nontraumatic hemorrhage were available for Ontario records only. In cases of twin or other multiple births, the mother's record was only associated with the first newborn's chart number. The database does not collect factors related to maternal weight (e.g., body mass index). For all maternal records, cases of shoulder dystocia, use of forceps, use of vacuum traction, breech delivery, caesarean section delivery, maternal impaired glucose tolerance, maternal gestational diabetes, and maternal preexisting diabetes were identified (Appendix 2). Twin or multiple births and episiotomy were available for Ontario records only.

\section{Referral to Multidisciplinary Centers}

The guideline development process involves addressing system performance. ${ }^{15}$ The creation of quality indicators for the referral process at clinically relevant time points is required to characterize gaps in care and to evaluate processes at baseline levels for future comparison. ${ }^{13}$ No definitive evidence exists for the association between OBPI outcomes and the timing of patient referral. Therefore, quality indicators were generated based on the best available evidence and expert consensus. ${ }^{43}$ Indicator selection was guided by criteria suggested by Mainz, ${ }^{43}$ who states that process indicators are most valuable when 1) management timeframes are short, 2) indicators address low-volume providers, and 3) patient prognosis cannot be stratified with a diagnostic investigation at baseline. ${ }^{43}$ These 3 conditions are present for OBPI.

The consensus group formally approved a set of quality indicators. Indicators were defined by the infant's age at the time of initial assessment at a multidisciplinary center; a designation of "good" indicates that assessment occurred by 1 month of age, "satisfactory" by 3 months of age, and "poor" thereafter. One month was chosen as the timeframe for a "good" designation based upon an existing algorithm for referral ${ }^{44}$ and a previous national position statement. ${ }^{4}$ Neuropraxic injuries are expected to completely recover by 1 month;4,7,12,66 beyond 1 month, recovery is not expected to be complete. ${ }^{4}$ The selection of 3 months for a "satisfactory" designation was based upon our meta-analysis ${ }^{18}$ and existing surgical algorithms, ${ }^{7,12}$ which support operative indications beginning at 3 months.

Referral data and timing were collected from available organizational and single-provider databases. Canadian OBPI multidisciplinary centers provided the aggregate number of infants assessed by multidisciplinary teams 
whose birth dates were within the same time range as the $\mathrm{CIHI}$ incidence data. Cases were dissociated; aggregates were pooled by province and compared with pooled incidence by province. Multidisciplinary centers also provided data on the proportion of patients seen in consultation by 1 month and by 3 months of age. No multidisciplinary OBPI care is delivered outside of these centers in Canada.

\section{Analysis}

Incidence was expressed per 1000 live births. Newborn and maternal risk factors were used to calculate the odds ratio (OR; descriptive statistic) for association with OBPI. We used criteria by Haddock et al.$^{33}$ to determine the strength of the association..$^{28}$ ORs of 3.0 or greater were considered "moderately strong" risk factors, and ORs of 0.33 or less were considered "moderately strong" protective factors. Further adapting Cohen's parameters, ${ }^{17}$ ORs of 30.0 or greater were considered "very strong" risk factors, and ORs of 0.033 or less were considered "very strong" protective factors.

The Joinpoint Regression Program was used to analyze the trend in OBPI incidence over the study period using the Monte Carlo Permutation method. ${ }^{36}$ Practically, this analysis computes a linear model for annual OBPI incidence and calculates the average annual percent change (AAPC) in incidence to determine if a significant trend (increase or decrease) is demonstrated in the model.

For incidence and risk factor analyses, Quebec data were removed post hoc, given the absence of coded OBPI cases in 2004-2005 prior to the adoption of ICD-10-CA and inconsistent reporting, since it was not mandatory in the province. In cases of missing data for calculating quality indicators, conservative estimates were imputed.

This study was reviewed and completed in accordance with guidelines from McMaster University's Research Ethics Board (REB), December 6, 2012.

\section{Results}

\section{Incidence}

The database included 2,762,996 infants born between 2004 and 2012. Of these newborns, 2968 were coded with OBPI (Table 1). Excluding the Quebec data, the OBPI incidence was 1.24 per 1000 births (95\% CI $1.20-1.29$ per 1000; Table 1). There was no significant change in annual incidence. Over the entire study period, AAPC was $-2.0 \%$ $(95 \% \mathrm{CI}-5.0 \%$ to $1.2 \%, \mathrm{p}=0.1)$.

\section{Risk Factors}

The strength of association for risk factors is listed in Table 2. Very strong risk factors included birth injury to humerus, shoulder dystocia, and clavicle fracture. Moderately strong risk factors included macrosomia ( $>4500$ $\mathrm{g}$ ), birth asphyxia, heavy for dates, pre-existing maternal diabetes, forceps traction, episiotomy, vacuum traction, and fetal asphyxia. Caesarean delivery was a moderately strong protective factor.

\section{Referral Processes}

Referral data were obtained from Canada's OBPI multi-

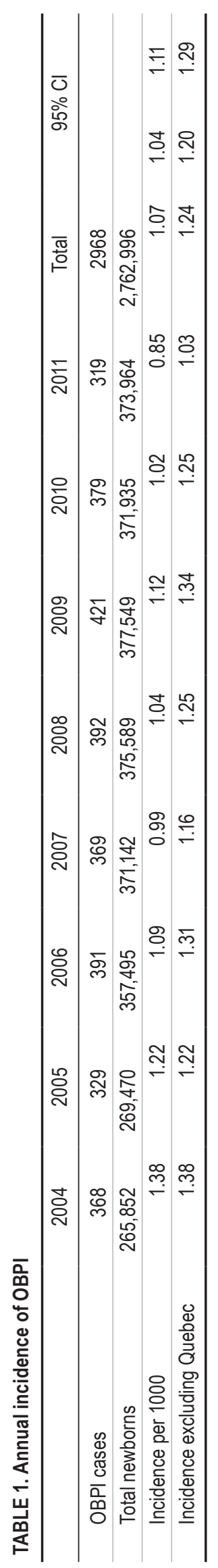


TABLE 2. Odds ratios for OBPI risk factors

\begin{tabular}{|c|c|c|c|c|}
\hline & $\begin{array}{c}\text { Incidence } \\
\text { (per } 1000 \\
\text { births) }\end{array}$ & $\begin{array}{l}\text { Odds } \\
\text { Ratio for } \\
\text { OBPI }\end{array}$ & $95^{\circ}$ & $6 \mathrm{Cl}$ \\
\hline Birth injury to humerus & 0.18 & 115.018 & 86.737 & 152.521 \\
\hline Shoulder dystocia & 28.37 & 59.849 & 55.49 & 64.549 \\
\hline Fracture of clavicle & 1.91 & 30.959 & 26.35 & 36.374 \\
\hline Macrosomia >4500 g & 11.54 & 12.602 & 11.305 & 14.048 \\
\hline Birth asphyxia* & 1.61 & 8.637 & 5.808 & 12.845 \\
\hline Heavy for dates* & 15.14 & 7.224 & 6.198 & 8.421 \\
\hline $\begin{array}{l}\text { Pre-existing maternal } \\
\text { diabetes }\end{array}$ & 6.18 & 5.754 & 4.711 & 7.028 \\
\hline Forceps traction & 26.38 & 5.43 & 4.869 & 6.056 \\
\hline Episiotomy* & 126.54 & 4.359 & 3.957 & 4.802 \\
\hline Vacuum traction & 73.07 & 3.483 & 3.188 & 3.806 \\
\hline Fetal asphyxia* & 3.65 & 3.46 & 2.292 & 5.226 \\
\hline $\begin{array}{l}\text { Impaired glucose } \\
\text { tolerance }\end{array}$ & 1.48 & 2.805 & 1.59 & 4.95 \\
\hline Gestational diabetes & 50.65 & 2.277 & 2.026 & 2.56 \\
\hline Breech delivery & 2.77 & 2.245 & 1.412 & 3.571 \\
\hline $\begin{array}{l}\text { Intracranial hemor- } \\
\text { rhage }^{*}\end{array}$ & 2.60 & 1.253 & 0.562 & 2.795 \\
\hline Twin or multiple births* & 15.38 & 0.446 & 0.253 & 0.786 \\
\hline Caesarean section & 268.31 & 0.152 & 0.129 & 0.179 \\
\hline
\end{tabular}

* Risk factors are determined using Ontario data only.

disciplinary centers for the study period (Table 3 ). Within Ontario, Western University data were not available. For sensitivity analysis, referrals for Western University were imputed using McMaster University's data, given the similar center sizes, catchments, and surgeons. Data for the University of Ottawa were available beginning in 2008 when the center's surgeon began practice. No referrals were imputed prior to 2008; OBPI cases were likely referred to other centers in the province. The surgeon representing Dalhousie University began practice after the reference timeframe, and no data were relevant. No referrals were imputed. Overall, multidisciplinary centers received 1188 OBPI referrals, $40 \%$ of the total cases identified by the CIHI database during the time period (Table 3). With sensitivity analysis as described above for Western University's data, referral to multidisciplinary centers increased to $1327(45 \%)$ nationally and to $715(51 \%)$ in Ontario.

For referrals, quality indicators are illustrated in Table 4. Overall, $28 \%$ of referred OBPI patients were assessed by multidisciplinary centers by 1 month of age ("good"), and $66 \%$ by 3 months ("satisfactory"). No center assessed the majority of referrals by 1 month of age. Six centers assessed the majority of referrals by 3 months of age. No data were imputed in quality indicator analyses.

\section{Discussion}

\section{Main Findings}

This is the first analysis of OBPI burden. This study contributes 3 findings to the literature. First, quality indi-
TABLE 3. OBPI referrals to Canadian multidisciplinary centers

\begin{tabular}{|c|c|c|c|}
\hline Province & Center(s) & $\begin{array}{c}\text { Patients } \\
\text { With } \\
\text { OBPI }\end{array}$ & $\begin{array}{l}\text { Referrals } \\
\text { (proportion } \\
\text { of provincial } \\
\text { referrals) }\end{array}$ \\
\hline $\begin{array}{l}\text { Martimes (NL, PE, } \\
\quad \mathrm{NS}, \mathrm{NB})\end{array}$ & Dalhousie & 244 & No center* \\
\hline Quebect & U de Montreal & 165 & $253(153 \%)$ \\
\hline \multirow[t]{5}{*}{ Ontario } & U of Toronto & \multirow[t]{5}{*}{1394} & $411(29 \%)$ \\
\hline & McMaster & & $139(10 \%)$ \\
\hline & U of Ottawał & & $26(2 \%)$ \\
\hline & Western & & Awaiting data \\
\hline & Total ON & & $576(41 \%)$ \\
\hline Manitoba & U of Manitoba & 152 & $51(34 \%)$ \\
\hline Saskatchewan & None & 149 & No center $(0 \%)$ \\
\hline \multirow[t]{3}{*}{ Alberta } & U of Alberta & \multirow[t]{3}{*}{448} & $103(23 \%)$ \\
\hline & U of Calgary & & $85(19 \%)$ \\
\hline & Total AB & & $188(42 \%)$ \\
\hline British Columbia & $\begin{array}{l}\text { U of British } \\
\text { Columbia }\end{array}$ & 404 & $120(30 \%)$ \\
\hline $\begin{array}{l}\text { Territories (YT, NT, } \\
\quad \mathrm{NU})\end{array}$ & None & 12 & No center $(0 \%)$ \\
\hline Total Canada & All & 2968 & $1188(40 \%)$ \\
\hline
\end{tabular}

cators for referral at clinically relevant time points were established, and a referral gap was characterized. Most infants $(55 \%-60 \%)$ were not referred to multidisciplinary centers for specialized management. Among those who were referred, only $28 \%$ received a referral by 1 month of age (i.e., timing designated as "good"). Second, a strength of association was calculated for risk factors; humeral fracture, shoulder dystocia, and clavicle fracture were identified as very strong risk factors for OBPI. Third, no trend in incidence was identified during the study period. Among mandatory reported data sets in Canada, OBPI incidence is 1.24 per 1000 births; all potential biases would underestimate OBPI identification. Implementation of a clinical practice guideline should target physician variation and improve referral timings.

\section{Incidence}

The Canadian incidence of OBPI is at least 1.24/1000 births, similar to many other well-known childhood conditions and disabilities. ${ }^{27,51-53}$ Potential biases would only underestimate the incidence since the database relies on diagnostic codes entered upon hospital discharge from primary care. The providers in the database may not accurately assess peripheral nerve injury ${ }^{22}$ and may fail to identify patients prior to newborn discharge. The incidence is consistent with similar studies of demographic populations, ${ }^{6,37,58}$ large United States samples, ${ }^{26,29}$ and hospital series. ${ }^{8,42,64}$

North American reports, ${ }^{31,57}$ multi-decade studies, ${ }^{16,65}$ 
TABLE 4. Timing of OBPI referral by center

\begin{tabular}{lccc}
\hline \multicolumn{1}{c}{ Center } & Referrals & $\begin{array}{c}\text { No. of } \\
\text { Referrals by } \\
1 \text { Month }\end{array}$ & $\begin{array}{c}\text { No. of } \\
\text { Referrals by } \\
3 \text { Months }\end{array}$ \\
\hline Dalhousie & No centert & - & - \\
\hline U de Montreal & 253 & $9(4 \%)$ & $125(49 \%)$ \\
\hline U of Toronto & 411 & $171(42 \%)$ & $297(72 \%)$ \\
\hline McMaster U & 139 & $46(33 \%)$ & $93(67 \%)$ \\
\hline U of Ottawał & 26 & $5(19 \%)$ & $10(38 \%)$ \\
\hline Western & Not available & - & - \\
\hline Total ON & 576 & $222(39 \%)$ & $400(69 \%)$ \\
\hline U of Manitoba & 51 & Awaiting & $38(75 \%)$ \\
\hline U of Alberta & 103 & $48(47 \%)$ & $84(82 \%)$ \\
\hline U of Calgary & 85 & $35(41 \%)$ & $60(71 \%)$ \\
\hline Total AB & 188 & $83(44 \%)$ & $144(77 \%)$ \\
\hline U of British Columbia & 120 & $23(19 \%)$ & $79(66 \%)$ \\
\hline Total Canada & 1188 & $337(28 \%)$ & $786(66 \%)$ \\
\hline
\end{tabular}

* Referrals by 3 months include 1 month data.

$\dagger$ Surgeon began practice after timeframe.

$\ddagger$ Surgeon began practice in 2008.

and dedicated educational intervention studies ${ }^{32}$ all report that OBPI incidence is consistent over time. The exception is Foad et al. ${ }^{29}$ who reported a decrease in annual incidence between 1997 and 2003. The study compared only 2 years (1997 vs 2003), with a decrease of 0.4 per 1000 births. This is similar to our data if only 2011 and 2004 were compared (1.38 vs 1.03 per 1000$)$. We performed a more robust analysis, confirming no change in annual incidence.

\section{Risk Factors}

Risk factors are consistent with a previous epidemiological study. ${ }^{29}$ However, this is the first study of risk factors to outline a strength of association. Maternal BMI ${ }^{25,46}$ and outcomes from previous deliveries ${ }^{1}$ are considered in practice but were not recorded in the database. While comorbid humerus and clavicle fractures are correlated with OBPI, these factors are not identified prior to labor and delivery; they occur concomitantly with OBPI itself. Thus, while these risks may alert primary care physicians to consider OBPI on a newborn examination, they are not detected at a stage to prevent OBPI.

Shoulder dystocia is the most significant potentially modifiable risk factor in terms of both prevention and effective management once identified during delivery. Dystocia-induced OBPI has been a focus of much research; dystocia is mechanically distinct, correlating with degree of neurological impairment, ${ }^{32}$ permanent impairment, ${ }^{50}$ and indication for nerve repair. ${ }^{54}$ Awareness of and dedicated training for dystocia maneuvers ${ }^{20,56}$ are reported to decrease the incidence of both overall and "permanent" OBPI in practice. ${ }^{24}$

\section{Referral Processes}

At best, only $45 \%$ of patients with OBPI were referred to multidisciplinary care. The proportion of referred cases was consistent across provinces. All potential biases lead to this number being overestimated, as it includes imputed data for 1 center. Further, we could not confirm Canadian birth for every child identified in our center referral databases, and there is a possibility that a small proportion of children were assessed at multiple centers. Estimates were consistent with the analysis of adult brachial plexus injury in the healthcare system;22 $48.6 \%$ of patients were referred to specialized centers, with $53.7 \%$ of referrals made late.

The timing of referral to a multidisciplinary center is important ${ }^{60}$ as a referral provides coordinated education for guardians and assessment by specialized physicians and therapists. One month was chosen as a timeframe for a designation of "good." The 1-month time point is conservative; a proportion of OBPI is neuropraxic and may resolve spontaneously by this time $(35 \%, 95 \%$ CI $23 \%-48 \%) .{ }^{18}$ A novel algorithm endorsed early referral for potential surgical candidates. ${ }^{44}$ However, primary care providers for newborns lack the familiarity and expertise to educate guardians and monitor for patient recovery. ${ }^{39,60}$ Recovery is often overestimated, and residual impairment is not characterized. ${ }^{18,55}$ Pediatric peripheral nerve management is a highly specialized treatment area, with physical therapy and operative resources concentrated at multidisciplinary centers. Centers and providers with high volumes of the same diagnosis (e.g., specialized centers) generally deliver higher-quality care in the pediatric population. ${ }^{45}$ This reflects the 1-month referral target endorsed by the consensus group here and a previous national multidisciplinary position statement. ${ }^{4}$

Three months was selected as "satisfactory" referral timing. While evidence is not sufficient to support specific nonoperative physical therapy protocols with referral at 1 month, ${ }^{10,18,63}$ there is growing evidence to support operative nerve repair beginning at 3 months of age. ${ }^{19}$ Canadian OBPI surgeons indicate preference for early referral ${ }^{4,7,12}$ to allow for serial assessment by a multidisciplinary team, with indications for nerve repair beginning at 3 months. ${ }^{7,12}$ The consensus group supported a conservative approach to referral, where centers can assess a proportion of children making a good recovery versus a patient with a delayed referral presenting with sequelae beyond ideal operative windows.

Beyond 3 months, referral timing is "poor," and 34\% of patients were assessed late. Given referral timing, they were almost certainly referred because of a persistent residual deficit beyond 3 months of age. Care in this group was not optimized.

\section{Strengths}

This study used a comprehensive, demographic sample from a publicly funded, universal healthcare system. Further, OBPI expertise is highly concentrated at 10 multidisciplinary centers in Canada; it is unlikely that specialized physical therapy or surgical expertise were available elsewhere during the study period. These characteristics of the healthcare system give us confidence in reporting outcomes for referral timing, risk factors, and incidence trends; little data were inaccessible to the authors.

A national group of experts established quality indicators for referral at clinically relevant time points. This was 
necessary given the lack of established quality indicators or definitive evidence for outcomes relative to referral timing. Risk factors and incidence trends have been previously investigated. However, we used rigorous methodology to express risk with strength of association calculations and confirmed no change in incidence. The burden of OBPI established by this study provides the foundation for the creation of a clinical practice guideline.

\section{Limitations}

This study has limitations inherent to observational and summarized data. The incidence of OBPI was likely to be underestimated. The CIHI database only captures infants born in the hospital. Discharge diagnoses are generated by primary care physicians and may not be accurate. Quebec does not have mandatory reporting; therefore, patient identification in that province was inconsistent. Conversely, referrals were likely to be overestimated. Data were generated from organizational or single-provider databases. The province and country of birth for each patient could not be verified. A proportion of patients may have been assessed at multiple centers. Data were imputed for 1 center. Still, the proportion of OBPI referrals to multidisciplinary centers was $45 \%$ at most.

The national database was limited. Known risk factors were not captured (maternal BMI, weight gain, and obesity). Newborn weight was limited to dichotomous variables, preventing a robust analysis. Patients with a total absence of risk factors could not be determined. Patientlevel data were not available to model multiple risk factors within a single patient. Data from provider databases were similarly limited. Annual referrals were not collected, and a trend could not be measured. However, the authors have no reason to believe that annual referrals have changed, since no intervention was applied. Patient-level OBPI severity, need for nerve repair, and ultimate outcome were not available. Outcomes for infants who were not referred are impossible to measure; care for this group was likely not optimized given the concentration of expertise at multidisciplinary centers in Canada.

\section{Next Steps}

This study is a component of an iterative process to improve the quality of OBPI care by creating a clinical practice guideline. OBPI management is limited by gaps, which include the timing of a multidisciplinary referral, ${ }^{44}$ concentrated clinical expertise, poor use of evidence, ${ }^{11,67}$ and variable surgical indications and timing. ${ }^{7}$ Given this clinical background where practice is heterogeneous and evidence is unclear, rigorous approaches to knowledge synthesis (e.g., clinical practice guidelines) have the greatest capacity to impact practice. ${ }^{68}$

The knowledge-to-action (KTA) cycle defines knowledge translation processes and designs research. ${ }^{61} \mathrm{~A}$ review of Canadian OBPI epidemiology provides knowledge inquiry. A systematic review of primary nerve repair provides a high-level of knowledge synthesis. With this evidence base established, a knowledge tool (i.e., clinical practice guideline) can be produced. Following implementation, quality indicators are used to monitor knowledge use and evaluate outcomes.
The Canadian OBPI Working Group networked the healthcare system's experts to address concentrated expertise. This study demonstrated that system performance is not optimized for OBPI in the healthcare system. Further, it established quality indicators and identified areas for improvement in system processes. A previous study ${ }^{18}$ investigated timing and indications for nerve repair. Together, these studies have optimized the evidence base. This new information can be used to reconcile the divergence of opinion between primary care providers and specialists, ${ }^{14}$ organize care for a prevalent and time-sensitive diagnosis, and provide consistent information to guardians. A guideline can optimize care by improving knowledge among clinicians, improving educated referral, influencing care processes at tertiary care centers, minimizing practice variation, informing policy, and establishing criteria and baselines for system evaluation. ${ }^{13}$

\section{Conclusions \\ Implications for Practice}

The incidence of OBPI was at least 1.24 per 1000 births with no trend. Infants whose delivery was complicated by humeral fracture, shoulder dystocia, or clavicle fracture were at very strong risk for OBPI; close examination of these infants may identify additional cases. A maximum of $45 \%$ of identified patients were referred to multidisciplinary care centers. Experts characterized referral timing as good (1 month) in 28\%, satisfactory ( 2 months) in $38 \%$, and poor (beyond 3 months) in $34 \%$ of patients.

\section{Implications for Research}

Shoulder dystocia is the strongest potentially modifiable risk factor for OBPI. This study provided the first quality indicators for OBPI referral. An OBPI referral gap has been established with quality indicators at clinically relevant time points; this gap can be addressed with knowledge tools to target referral and practice variation.

\section{Acknowledgments}

This work was supported by the following grants and awards: the Canadian Institutes of Health Research (CIHR) Master's Award; Frederick Banting and Charles Best Award; Father Sean O'Sullivan Research Centre Award, St. Joseph's Healthcare, Hamilton, Ontario, Canada; and the Juravinski Surgical Fellowship, Department of Surgery, McMaster University, Hamilton, Ontario, Canada. We would like to thank Marija Bucevska, Angela Chiu, Carol DeMatteo, Deborah Gjertsen, Emily Ho, and Kathleen O'Grady for data contributions.

The Canadian OBPI Working Group: James Bain, Michael Bezuhly, Sean Bristol, Kevin Cheung, Howard Clarke, Kristen Davidge, Robertson Harrop, Jennifer Lin, Jaret Olson, Douglas Ross, Constantin Stanciu, David Tang, Susan Thompson, Cynthia Verchere, and Yvonne Ying.

\section{References}

1. al-Qattan MM, al-Kharfy TM: Obstetric brachial plexus injury in subsequent deliveries. Ann Plast Surg 37:545-548, 1996

2. al-Qattan MM, el-Sayed AAF, al-Zahrani AY, al-Mutairi SA, al-Harbi MS, al-Mutairi AM, et al: Obstetric brachial plexus palsy: a comparison of affected infants delivered vaginally 
by breech or cephalic presentation. J Hand Surg Eur Vol 35:366-369, 2010

3. al-Qattan MM, el-Sayed AAF, al-Zahrani AY, al-Mutairi SA, al-Harbi MS, al-Mutairi AM, et al: Obstetric brachial plexus palsy in newborn babies of diabetic and non-diabetic mothers. J Hand Surg Eur Vol 35:362-365, 2010

4. Andersen J, Watt J, Olson J, Van Aerde J: Perinatal brachial plexus palsy. Paediatr Child Health 11:93-100, 2006

5. Ashrafzadeh F, Boskabadi H, Faraji Rad M, Seyyed Hosseinee P: A study on the risk factors for obstetrical brachial plexus palsy. Iran J Child Neurol 4:13-18, 2010

6. Bager B: Perinatally acquired brachial plexus palsy-a persisting challenge. Acta Paediatr 86:1214-1219, 1997

7. Bain JR, Dematteo C, Gjertsen D, Hollenberg RD: Navigating the gray zone: a guideline for surgical decision making in obstetrical brachial plexus injuries. J Neurosurg Pediatr 3:173-180, 2009

8. Baskett TF, Allen AC: Perinatal implications of shoulder dystocia. Obstet Gynecol 86:14-17, 1995

9. Bellew M, Kay SP: Early parental experiences of obstetric brachial plexus palsy. J Hand Surg Br 28:339-346, 2003

10. Bialocerkowski A, Kurlowicz K, Vladusic S, Grimmer K: Effectiveness of primary conservative management for infants with obstetric brachial plexus palsy. Int J Evid-Based Healthc 3:27-44, 2005

11. Bodensteiner JB, Rich KM, Landau WM: Early infantile surgery for birth-related brachial plexus injuries: justification requires a prospective controlled study. J Child Neurol 9:109-110, 1994

12. Borschel GH, Clarke HM: Obstetrical brachial plexus palsy. Plast Reconstr Surg 124 (1 Suppl):144e-155e, 2009

13. Brouwers MC, Stacey D, O'Connor AM: Knowledge translation tools, in Straus SE, Tetroe J, Graham ID (eds): Knowledge Translation in Health Care: Moving from Evidence to Practice, ed 1. West Sussex, UK: Wiley-Blackwell, 2009

14. Burgers JS, Smolders M, van der Weijden T, Davis D, Grol $\mathrm{R}$ : Clinical practice guidelines as a tool for improving patient care, in Grol R, Wensing M, Eccles M, et al (eds): Improving Patient Care: The Implementation of Change in Health Care, ed 2. West Sussex, UK: Wiley-Blackwell, 2013

15. Cancer Care Ontario: Program in Evidence-Based Care Handbook. (https://www.cancercare.on.ca/common/pages/ UserFile.aspx?fileId=50876) [Accessed August 7, 2015]

16. Chauhan SP, Rose CH, Gherman RB, Magann EF, Holland MW, Morrison JC: Brachial plexus injury: a 23-year experience from a tertiary center. Am J Obstet Gynecol 192:17951802,2005

17. Cohen J: Statistical Power Analysis for the Behavioral Sciences. Mahwah, NJ: Lawrence Erlbaum Associates, 1988

18. Coroneos CJ, Voineskos SH, Coroneos MK, Alolabi N, Goekjian SR, Willoughby LI, et al: Primary nerve repair for obstetrical brachial plexus injury (OBPI): a meta-analysis. Plast Reconstr Surg 36:765-779, 2015

19. Coroneos CJ, Voineskos SH, Coroneos MK, Alolabi N, Goekjian SR, Willoughby LI, et al: Obstetrical brachial plexus injury (OBPI): a national clinical practice guideline. Plast Reconstr Surg 133 (4 Suppl):1031, 2014 (Abstract)

20. Crofts JF, Ellis D, James M, Hunt LP, Fox R, Draycott TJ: Pattern and degree of forces applied during simulation of shoulder dystocia. Am J Obstet Gynecol 197:156.e1-156.e6, 2007

21. Dawodu A, Sankaran-Kutty M, Rajan TV: Risk factors and prognosis for brachial plexus injury and clavicular fracture in neonates: a prospective analysis from the United Arab Emirates. Ann Trop Paediatr 17:195-200, 1997

22. Dolan RT, Butler JS, Hynes DE, Cronin KJ: The nerve to delay: the impact of delayed referrals in the management of traumatic brachial plexus injuries in the Republic of Ireland. J Plast Reconstr Aesthet Surg 65:1127-1129, 2012
23. Donnelly V, Foran A, Murphy J, McParland P, Keane D, O'Herlihy C: Neonatal brachial plexus palsy: an unpredictable injury. Am J Obstet Gynecol 187:1209-1212, 2002

24. Draycott TJ, Crofts JF, Ash JP, Wilson LV, Yard E, Sibanda $\mathrm{T}$, et al: Improving neonatal outcome through practical shoulder dystocia training. Obstet Gynecol 112:14-20, 2008

25. El-Chaar D, Finkelstein SA, Tu X, Fell DB, Gaudet L, Sylvain J, et al: The impact of increasing obesity class on obstetrical outcomes. J Obstet Gynaecol Can 35:224-233, 2013

26. Evans-Jones G, Kay SPJ, Weindling AM, Cranny G, Ward A, Bradshaw A, et al: Congenital brachial palsy: incidence, causes, and outcome in the United Kingdom and Republic of Ireland. Arch Dis Child Fetal Neonatal Ed 88:F185-F189, 2003

27. Farrell P, Joffe S, Foley L, Canny GJ, Mayne P, Rosenberg M: Diagnosis of cystic fibrosis in the Republic of Ireland: epidemiology and costs. Ir Med J 100:557-560, 2007

28. Ferguson CJ: An effect size primer: A guide for clinicians and researchers. Prof Psychol Res Pr 40:532-538, 2009

29. Foad SL, Mehlman CT, Ying J: The epidemiology of neonatal brachial plexus palsy in the United States. J Bone Joint Surg Am 90:1258-1264, 2008

30. Gherman RB, Ouzounian JG, Miller DA, Kwok L, Goodwin TM: Spontaneous vaginal delivery: a risk factor for Erb's palsy? Am J Obstet Gynecol 178:423-427, 1998

31. Gordon M, Rich H, Deutschberger J, Green M: The immediate and long-term outcome of obstetric birth trauma. I. Brachial plexus paralysis. Am J Obstet Gynecol 117:51-56, 1973

32. Gurewitsch ED, Johnson E, Hamzehzadeh S, Allen RH: Risk factors for brachial plexus injury with and without shoulder dystocia. Am J Obstet Gynecol 194:486-492, 2006

33. Haddock CK, Rindskopf D, Shadish WR: Using odds ratios as effect sizes for meta-analysis of dichotomous data: A primer on methods and issues. Psychol Methods 3:339-353, 1998

34. Hoeksma AF, Wolf H, Oei SL: Obstetrical brachial plexus injuries: incidence, natural course and shoulder contracture. Clin Rehabil 14:523-526, 2000

35. Jackson ST, Hoffer MM, Parrish N: Brachial-plexus palsy in the newborn. J Bone Joint Surg Am 70:1217-1220, 1988

36. Kim HJ, Fay MP, Feuer EJ, Midthune DN: Permutation tests for joinpoint regression with applications to cancer rates. Stat Med 19:335-351, 2000

37. Kolderup LB, Laros RK Jr, Musci TJ: Incidence of persistent birth injury in macrosomic infants: association with mode of delivery. Am J Obstet Gynecol 177:37-41, 1997

38. Lagerk vist AL, Johansson U, Johansson A, Bager B, Uvebrant P: Obstetric brachial plexus palsy: a prospective, population-based study of incidence, recovery, and residual impairment at 18 months of age. Dev Med Child Neurol 52:529-534, 2010

39. Laurent JP: Neurosurgical intervention for birth-related brachial plexus injuries. Neurosurg Q 7:69-75, 1997

40. Liljestrand J: Reducing perinatal and maternal mortality in the world: the major challenges. Br J Obstet Gynaecol 106:877-880, 1999

41. Lindqvist PG, Erichs K, Molnar C, Gudmundsson S, Dahlin LB: Characteristics and outcome of brachial plexus birth palsy in neonates. Acta Paediatr 101:579-582, 2012

42. Lipscomb KR, Gregory K, Shaw K: The outcome of macrosomic infants weighing at least 4500 grams: Los Angeles County + University of Southern California experience. Obstet Gynecol 85:558-564, 1995

43. Mainz J: Defining and classifying clinical indicators for quality improvement. Int J Qual Health Care 15:523-530, 2003

44. Malessy MJA, Pondaag W, Yang LJS, Hofstede-Buitenhuis SM, le Cessie S, van Dijk JG: Severe obstetric brachial plexus palsies can be identified at one month of age. PLoS One 6:e26193, 2011 
45. Mangione-Smith R, McGlynn EA: Assessing the quality of healthcare provided to children. Health Serv Res 33:10591090, 1998

46. Mochhoury L, Razine R, Kasouati J, Kabiri M, Barkat A: Body mass index, gestational weight gain, and obstetric complications in Moroccan population. J Pregnancy 2013:379461, 2013

47. Mollberg M, Lagerkvist AL, Johansson U, Bager B, Johansson A, Hagberg H: Comparison in obstetric management on infants with transient and persistent obstetric brachial plexus palsy. J Child Neurol 23:1424-1432, 2008

48. Mollberg M, Wennergren M, Bager B, Ladfors L, Hagberg H: Obstetric brachial plexus palsy: a prospective study on risk factors related to manual assistance during the second stage of labor. Acta Obstet Gynecol Scand 86:198-204, 2007

49. Narchi H, Kulaylat NA, Ekuma-Nkama E: Clavicle fracture and brachial plexus palsy in the newborn: Risk factors and outcome. Ann Saudi Med 16:707-710, 1996

50. Nehme A, Kany J, Sales-De-Gauzy J, Charlet JP, Dautel G, Cahuzac JP: Obstetrical brachial plexus palsy. Prediction of outcome in upper root injuries. J Hand Surg Br 27:9-12, 2002

51. Newhook LA, Penney S, Fiander J, Dowden J: Recent incidence of type 1 diabetes mellitus in children $0-14$ years in Newfoundland and Labrador, Canada climbs to over 45/100,000: a retrospective time trend study. BMC Res Notes 5:628, 2012

52. Newschaffer CJ, Croen LA, Daniels J, Giarelli E, Grether JK, Levy SE, et al: The epidemiology of autism spectrum disorders. Annu Rev Public Health 28:235-258, 2007

53. Patel H, Feldman M: Universal newborn hearing screening. Paediatr Child Health 16:301-310, 2011

54. Pondaag W, Allen RH, Malessy MJA: Correlating birthweight with neurological severity of obstetric brachial plexus lesions. BJOG 118:1098-1103, 2011

55. Pondaag W, Malessy MJA, van Dijk JG, Thomeer RTWM: Natural history of obstetric brachial plexus palsy: a systematic review. Dev Med Child Neurol 46:138-144, 2004

56. Revicky V, Mukhopadhyay S, Morris EP, Nieto JJ: Can we predict shoulder dystocia? Arch Gynecol Obstet 285:291295, 2012

57. Rubin A: Birth injuries: incidence, mechanisms, and end results. Obstet Gynecol 23:218-221, 1964

58. Sjöberg I, Erichs K, Bjerre I: Cause and effect of obstetric (neonatal) brachial plexus palsy. Acta Paediatr Scand 77:357-364, 1988

59. Soni AL, Mir NA, Kishan J, Faquih AM, Elzouki AY: Brachial plexus injuries in babies born in hospital: an appraisal of risk factors in a developing country. Ann Trop Paediatr 5:69-71, 1985

60. Squitieri L, Larson BP, Chang KWC, Yang LJS, Chung KC: Medical decision-making among adolescents with neonatal brachial plexus palsy and their families: a qualitative study. Plast Reconstr Surg 131:880e-887e, 2013

61. Straus SE, Tetroe J, Graham ID: Knowledge to action: what it is and what it isn't, in Straus SE, Tetroe J, Graham ID (eds): Knowledge Translation in Health Care: Moving from Evidence to Practice, ed 1. West Sussex, UK: Blackwell, 2009, pp 3-11
62. Tan KL: Brachial palsy. J Obstet Gynaecol Br Commonw 80:60-62, 1973

63. ter Steeg AM, Hoeksma AF, Dijkstra PF, Nelissen RGHH, De Jong BA: Orthopaedic sequelae in neurologically recovered obstetrical brachial plexus injury. Case study and literature review. Disabil Rehabil 25:1-8, 2003

64. Walle T, Hartikainen-Sorri AL: Obstetric shoulder injury. Associated risk factors, prediction and prognosis. Acta Obstet Gynecol Scand 72:450-454, 1993

65. Walsh JM, Kandamany N, Ni Shuibhne N, Power H, Murphy JF, O'Herlihy C: Neonatal brachial plexus injury: comparison of incidence and antecedents between 2 decades. Am J Obstet Gynecol 204:324.e1-324.e6, 2011

66. Waters PM: Comparison of the natural history, the outcome of microsurgical repair, and the outcome of operative reconstruction in brachial plexus birth palsy. J Bone Joint Surg Am 81:649-659, 1999

67. Waters PM, Bae DS: Brachial plexus birth palsy: rationale for a multicenter prospective study. Semin Plast Surg 18:377384,2004

68. Wong RKS, Brierley J, Brouwers M: What is the best way to produce consensus and buy in to guidelines for rectal cancer? Curr Colorectal Cancer Rep 8:83-89, 2012

\section{Disclosure}

The authors report no conflict of interest concerning the materials or methods used in this study or the findings specified in this paper.

\section{Author Contributions}

Conception and design: Bain, CJ Coroneos, Voineskos, MK Coroneos, Farrokhyar, Thoma, Brouwers. Acquisition of data: CJ Coroneos, Voineskos, MK Coroneos, Alolabi, Goekjian, Willoughby. Analysis and interpretation of data: CJ Coroneos, Voineskos, Farrokhyar, Brouwers. Drafting the article: CJ Coroneos, Voineskos, MK Coroneos, Alolabi, Goekjian, Willoughby, Farrokhyar. Critically revising the article: Bain, CJ Coroneos, MK Coroneos, Thoma, Brouwers. Reviewed submitted version of manuscript: Bain, CJ Coroneos, Voineskos, MK Coroneos, Alolabi, Goekjian, Willoughby, Thoma, Brouwers. Approved the final version of the manuscript on behalf of all authors: Bain. Statistical analysis: CJ Coroneos, Farrokhyar. Administrative/technical/material support: Bain, Voineskos, MK Coroneos, Alolabi, Goekjian, Willoughby, Thoma, Brouwers. Study supervision: Bain, Farrokhyar, Thoma, Brouwers.

\section{Supplemental Information \\ Online-Only Content}

Supplemental material is available with the online version of the article.

Appendix 1 and Appendix 2. http://thejns.org/doi/ suppl/10.3171/2015.6.PEDS14703.

\section{Correspondence}

James R. Bain, McMaster Medical Centre, HSC 4E16, 1200 Main St. W, Hamilton, ON L8N 3Z5, Canada. email: bainj@hhsc.ca. 